\title{
Effect of endogenous carbohydrate availability on oral medium-chain triglyceride oxidation during prolonged exercise.
}

Citation for published version (APA):

Jeukendrup, A. E., Saris, W. H. M., van Diesen, R., Brouns, F. J. P. H., \& Wagenmakers, A. J. M. (1996). Effect of endogenous carbohydrate availability on oral medium-chain triglyceride oxidation during prolonged exercise. Journal of Applied Physiology, 80(3), 949-954.

https://doi.org/10.1152/jappl.1996.80.3.949

Document status and date:

Published: 01/01/1996

DOI:

10.1152/jappl.1996.80.3.949

Document Version:

Publisher's PDF, also known as Version of record

\section{Please check the document version of this publication:}

- A submitted manuscript is the version of the article upon submission and before peer-review. There can be important differences between the submitted version and the official published version of record.

People interested in the research are advised to contact the author for the final version of the publication, or visit the DOI to the publisher's website.

- The final author version and the galley proof are versions of the publication after peer review.

- The final published version features the final layout of the paper including the volume, issue and page numbers.

Link to publication

\footnotetext{
General rights rights.

- You may freely distribute the URL identifying the publication in the public portal. please follow below link for the End User Agreement:

www.umlib.nl/taverne-license

Take down policy

If you believe that this document breaches copyright please contact us at:

repository@maastrichtuniversity.nl

providing details and we will investigate your claim.
}

Copyright and moral rights for the publications made accessible in the public portal are retained by the authors and/or other copyright owners and it is a condition of accessing publications that users recognise and abide by the legal requirements associated with these

- Users may download and print one copy of any publication from the public portal for the purpose of private study or research.

- You may not further distribute the material or use it for any profit-making activity or commercial gain

If the publication is distributed under the terms of Article $25 \mathrm{fa}$ of the Dutch Copyright Act, indicated by the "Taverne" license above, 


\title{
Effect of endogenous carbohydrate availability on oral medium-chain triglyceride oxidation during prolonged exercise
}

\author{
ASKER E. JEUKENDRUP, WIM H. M. SARIS, RICHARD VAN DIESEN, \\ FRED BROUNS, AND ANTON J. M. WAGENMAKERS \\ Department of Human Biology, Nutrition Research Center, \\ University of Limburg, 6200 MD Maastricht, The Netherlands
}

\begin{abstract}
Jeukendrup, Asker E., Wim H. M. Saris, Richard Van Diesen, Fred Brouns, and Anton J. M. Wagenmakers. Effect of endogenous carbohydrate availability on oral medium-chain triglyceride oxidation during prolonged exercise. J. Appl. Physiol. 80(3): 949-954, 1996.-The present study examined the medium-chain triglyceride (MCT) oxidation rate of oral carbohydrate (CHO)+MCrT supplements after a glycogen-depletion trial [low glycogen (LG)] and in the glycogen-loaded state [normal-to-high glycogen (HG)]. Eight elite athletes cycled four times 90 min at $50 \%$ maximal workload (57\% maximal $\mathrm{O}_{2}$ uptake). In two trials, they followed a $\mathrm{LG}$ protocol to achieve low-glycogen stores in the leg muscles the evening before the experiment, and in two trials they followed a $H G$ protocol. Subjects received a bolus of $4 \mathrm{ml} / \mathrm{kg}$ at the start and $2 \mathrm{ml} / \mathrm{kg}$ every $20 \mathrm{~min}$ during exercise of either a $15 \% \mathrm{CHO}$ (long-chain glucose polymer) solution or an equicaloric $\mathrm{CHO}+\mathrm{MCT}$ suspension. Exogenous MCT oxidation was measured by adding a $\left[1,1,1-{ }^{13} \mathrm{C}\right]$ trioctanoate tracer to the MCT oil and measuring ${ }^{13} \mathrm{CO}_{2}$ production in the breath. The results show that $85 \%$ of MCT ingested was oxidized in LG and $69 \%$ in $\mathrm{HG}$ during the 60 - to 90 -min period. There was no statistically significant difference in MCT utilization between $\mathrm{LG}$ and HG. Peak oxidation rates were 0.15 and $0.13 \mathrm{~g} / \mathrm{min}$, respectively. MCT contributed $7.6 \%$ (LG) and $6.5 \%$ (HG) to total energy expenditure during the 60- to 90-min period. Total fatty acid oxidation was significantly elevated in the LG trial but was not influenced by MCT ingestion. Concomitantly, CHO oxidation was reduced in LG but no effect of MCT was observed. We conclude that 1 ) the contribution of MCT to total energy expenditure was small and 2) strenuous exercise the day before the experiment, followed by a low CHO intake and leading to a low CHO availability, substantially increased total fat oxidation but did not significantly increase MCT oxidation.
\end{abstract}

trioctanoate; carbohydrate supplementation; substrate utilization; carbon-13 labeling; stable isotopes; exercise; ketone bodies

BECAUSE OF THIEIR PIIYSICAL characteristics, mediumchain triglycerides (MCT) are frequently used in parenteral and enteral nutrition. It is thought that MCT are a readily available energy source because they have been shown to be rapidly absorbed (2) and, unlike long-chain fatty acids, which are transported in chylomicrons through the lymphatic system, medium-chain fatty acids (MCFA) can directly enter the bloodstream through the portal system. In addition, at the cellular level, MCFA can cross the inner mitochondrial membrane in the liver and muscle independently of the acylcarnitine transferase system (4).

Therefore, it has been suggested that MCT might be a readily available energy source for the working muscle. When ingested orally during exercise, MCT could provide an energy substrate in addition to carbohydrates (CHO). Massicotte et al. (16) suggested that the energetic contribution of exogenous MCT was only slightly lower than that of an equicaloric glucose load during prolonged exercise of moderate intensity. Our laboratory recently reported that $70 \%$ of the ingested MCT was oxidized during exercise when coingested with CHOs (12).

As exercise progresses, muscle glycogen levels decline, and this decline is accompanied by a shift in substrate utilization from $\mathrm{CHO}$ to fat.

Plasma free fatty acid (FFA) uptake and oxidation increase during exercise $(10,26)$. Also, plasma glucose turnover and oxidation are increased during exercise at moderate intensities $(22,29)$. Thus, when intramuscular fuel stores decrease during exercise, there is an increased reliance on plasma fatty acids and plasma glucose for energy provision. We hypothesized that a CHO-MCT supplement can be especially effective under conditions where the reliance on blood substrates is maximal, such as in a glycogen-depleted state. Therefore, the present study examined the metabolic response to CIO +MCT supplementation with low muscle glycogen (LG) and normal-to-high muscle glycogen $(\mathrm{HG})$ stores in a randomized crossover design. To study the oxidation rate of exogenous MCT during exercise, a $\left[1,1,1{ }^{13} \mathrm{C}\right]$ trioctanoate tracer was incorporated in the drink.

\section{METHODS}

Subjects. Eight male highly trained elite triathletes or cyclists [age $28.9 \pm 2.5 \mathrm{yr}$, weight $77.9 \pm 3.0 \mathrm{~kg}$, height $184.5 \pm 3.1 \mathrm{~cm}$, maximal work rate $434 \pm 14 \mathrm{~W}$, and maximul $\mathrm{O}_{2}$ consumption $\left.\left(\mathrm{VO}_{2 \operatorname{mnx}}\right) 70 \stackrel{2}{ } 2 \mathrm{ml} \cdot \mathrm{kg}^{-1} \cdot \mathrm{min}^{-1}\right]$ competing at: the international level participated in this study. The nature and the risks of the experimental procedures were explained to the subjects, and their written informed consent was obtained. The study was approved by the local medical ethical committee.

Pretrials. Subjects' maximal worluload (Wmax) was attained on an electronically braked ergometer (Lode Excalibur Sport, Groningen, The Netherlands) during an incremental exhaustive-exercise test (14) 1 wk before the first experimental trial. The resultis of this initial test were used to determine the 50\% Wmax, which was later used in the experimental trials.

Subjects randomly performed two glycogen-depletion trials to achieve LG stores and two glycogen-loading trials (FG). The depletion trial was always performed in the evening 
Table 1. Steady-state $\mathrm{VO}_{2}$ and $\dot{V}_{\mathrm{CO}}$ values at different time points during 90 min of exercise in subjects ingesting CHO or a CHO +MCT mixture with normal-to-high glycogen or low glycogen levels

\begin{tabular}{|c|c|c|c|c|c|c|}
\hline & \multicolumn{6}{|c|}{ Time, min } \\
\hline & 1.5 & 30 & 45 & 60 & 75 & 90 \\
\hline \multicolumn{7}{|c|}{$\dot{\mathrm{V}} \mathrm{O}_{2}, \mathrm{l} / \mathrm{min}$} \\
\hline $\begin{array}{l}\mathrm{LG}-\mathrm{CHO} \\
\mathrm{LG}-\mathrm{CHO}+\mathrm{MCT} \\
\mathrm{HG}-\mathrm{CHO} \\
\mathrm{HG}-\mathrm{CHO}+\mathrm{MCT}\end{array}$ & $\begin{array}{l}3.17 \pm 0.09 \\
3.25 \pm 0.11 \\
3.00 \pm 0.08 \\
3.07 \pm 0.08\end{array}$ & $\begin{array}{l}3.24 \pm 0.10 \\
3.24 \pm 0.10 \\
3.03 \pm 0.09 \\
3.15 \pm 0.08\end{array}$ & $\begin{array}{l}3.25 \pm 0.10 \\
3.32 \pm 0.10 \\
3.01 \pm 0.08 \\
3.17 \pm 0.11\end{array}$ & $\begin{array}{l}3.24 \pm 0.08 \\
3.25 \pm 0.11 \\
3.06 \pm 0.11 \\
3.19 \pm 0.11\end{array}$ & $\begin{array}{l}3.25 \pm 0.11 \\
3.28 \pm 0.11 \\
3.06 \pm 0.07 \\
3.23 \pm 0.10\end{array}$ & $\begin{array}{l}3.36 \pm 0.10 \\
3.31 \pm 0.11 \\
3.04 \pm 0.10 \\
3.20 \pm 0.12\end{array}$ \\
\hline \multicolumn{7}{|c|}{$\dot{\mathrm{V} C \mathrm{O}_{2}}, l / \mathrm{min}$} \\
\hline $\begin{array}{l}\text { LG-CHO } \\
\text { LG-CHO + MCT } \\
\text { HGG-CHO } \\
\text { HIG-CHO + MCT }\end{array}$ & $\begin{array}{l}2.61 \pm 0.07 \\
2.64 \pm 0.08 \\
2.67 \pm 0.09 \\
2.70 \pm 0.08\end{array}$ & $\begin{array}{l}2.62 \pm 0.08 \\
2.62 \pm 0.08 \\
2.67 \pm 0.09 \\
2.74 \pm 0.08\end{array}$ & $\begin{array}{l}2.61 \pm 0.08 \\
2.59 \pm 0.07 \\
2.63 \pm 0.08 \\
2.71 \pm 0.10\end{array}$ & $\begin{array}{l}2.59 \pm 0.08 \\
2.57 \pm 0.07 \\
2.65 \pm 0.11 \\
2.66 \pm 0.08\end{array}$ & $\begin{array}{l}2.63 \pm 0.10 \\
2.57 \pm 0.07 \\
2.62 \pm 0.09 \\
2.70 \pm 0.08\end{array}$ & $\begin{array}{l}2.69 \pm 0.09 \\
2.63 \pm 0.08 \\
2.60 \pm 0.11 \\
2.74 \pm 0.11\end{array}$ \\
\hline
\end{tabular}

Values are means $\pm \mathrm{SE} ; n=8$ subjects. $\dot{\mathrm{VO}}_{2}, \mathrm{O}_{2}$ uptake; $\dot{\mathrm{VCO}}_{2}, \mathrm{CO}_{2}$ production. LG, low glycogen; HG, normal-to-high glycogen; CHO, carbohydrate; MCT, medium-chain triglycerides.

(8-10 P.M.) preceding the experimental trial. An intermittent exercise protocol was employed, consisting of 2 -min bouts at $90 \%$ Wmax interspersed with 2 min at $50 \%$ Wmax. When the subjects were unable to complete the 2-min 90\% Wmax, the high workload was subsequently lowered to 80,70 , and $60 \%$ Wmax. The exercise was stopped when the 2-min trial at $60 \%$ Wmax could not be completed any more. This protocol has previously been shown to lead to very low muscle glycogen levels ( $<150 \mu \mathrm{mol} / \mathrm{g}$ dry wt) (1.3). Subjects were allowed to eat two crackers with cheese (14. $\mathrm{g}$ CHO, $4 \mathrm{~g}$ fat, $6 \mathrm{~g}$ protein) and to drink a cup of coffee or tea in the time between completion of the glycogen-depletion protocol and going to sleep.

The HG trials were preceded by a CHO-rich meal $(4,000-$ $5,000 \mathrm{~kJ} ; \pm 80 \% \mathrm{CHO}, \pm 10 \%$ fat, $\pm 10 \%$ protein) at the laboratory, the evening before the experimental test $(8-10$ P.M.), to ensure a high $\mathrm{CHO}$ intake and concomitant $\mathrm{HG}$ stores.

Experimental trials. Each subject performed four trials, each separated by at least 7 days. A trial consisted of 90-min cycling at $50 \% \mathrm{Wmax}\left(\sim 57 \% \dot{\mathrm{VO}}_{2 \max }\right) . \mathrm{O}_{2}$ uptake $\left(\dot{\mathrm{V}} \mathrm{O}_{2}\right)$ data are presented in Table 1 . Drinks were provided in a randomized order, and both the subjects and the experiment leader were unaware of the content of the drink. Subjects were instructed not to consume any products with a high natural abundance of ${ }^{13} \mathrm{C}$ during the entire experimental period.

Protocol. Subjects reported to the laboratory at 8:00 A.M. after an overnight fast, and a standardized breakfast of two crackers with cheese ( $14 \mathrm{~g}$ CHO $4 \mathrm{~g}$ fat, and $6 \mathrm{~g}$ protein) was provided. A Teflon catheter (Baxter Quick Cath, Dupont, Ireland) was inserted into an antecubital vein, and at 8:30 A.M. a resting blood sample was drawn. Resting breath gases were collected for the measurement of $\mathrm{VO}_{2}$ (SensorMedics 2900 analyzer, Anaheim, CA), and Vacutainer tubes were filled directly from the mixing chamber in duplicate to determine the ${ }^{13} \mathrm{C} /{ }^{12} \mathrm{C}$ ratio in expired $\mathrm{CO}_{2}$. At 8:50 A.M., a 10-min warm-up began at $100 \mathrm{~W}$. At 9:00 A.M., subjects started cycling at 50\% Wmax for $90 \mathrm{~min}$, and in the first minute they drank an initial bolus $(4 \mathrm{ml} / \mathrm{kg}$ ) of either one of the test drinks. Thereafter, every $20 \mathrm{~min}$, a beverage volume of $2 \mathrm{ml} / \mathrm{kg}$ was given. Blood samples were drawn at 5,10 , and $15 \mathrm{~min}$ and every $15 \mathrm{~min}$ thereafter. Expiratory gases were collected every $15 \mathrm{~min}$. Two subjects were tested on the same day, starting the protocol 4 min apart.

Drinks. The drinks consisted of tapioca-clerived long-chain glucose polymers of 10 w ${ }^{13} \mathrm{C}$ natural abundance (Sandor
Nutrition, Bern, Switzerland) or a mixture of CHO and MCT. The MCT contained fatty acids with a chain length of $99 \% \mathrm{C} 8$ (Estasan GT8-99, Unichema, Barcelona, Spain). To all drinks, $20 \mathrm{mmol} / \mathrm{l}$ of $\mathrm{NaCl}$ were added.

The composition of the drinks is listed in Table 2. On average, subjects ingested $146.0 \mathrm{~g}$ CHO in the CHO trials and $87.1 \mathrm{~g}$ CHO plus $26.6 \mathrm{~g}$ MCT in the CHO +MCT experiments.

The CHO solution and the CHO + MCT suspension containing $40 \%$ (by energy) MCT were equicaloric. Drink temperature was kept constant at $20^{\circ} \mathrm{C}$.

Tracer methodology A $[1,1,1-1: \mathrm{C}]$ trioctanoate treacer (99\%), purchased from Cambridge Isotope Laboratories (Woburn MA), was incorporated in the unlabeled MCT suspension and then mixed with the CHO to form a stable suspension. The ${ }^{13} \mathrm{C}$ enrichment of the MCT was $+160.618 \%(0.013042$ ${ }^{13} \mathrm{C} /{ }^{12} \mathrm{C}$ ratio), whereas the ${ }^{13} \mathrm{C}$ enrichment of the $\mathrm{CHO}$ was $-26.12 \delta \%$ o $\left(0.0112372^{13} \mathrm{C} /{ }^{12} \mathrm{C}\right.$ ratio). The enrichment of the CHO was about the same as the average enrichment of the subjects' resting expired air $(-27.218 \%(\%)$.

In the present study and in previous studies from our laboratory $(12,20,24,27,28)$, we have shown that instructing the subjects not to eat any products of high- ${ }^{19} \mathrm{C}$ abundance during the experimental period was effective in reducing the background shift (change in ${ }^{14} \mathrm{CO}_{2}$ ) from ondogenous substrate stores (28). We nevertheless decided to correct the background with the change of the ${ }^{19} \mathrm{C}$ enrichment of breath samples observed in the CHO trial (Table 3).

During the initial phases of exercise, some retention of ${ }^{12} \mathrm{CO}_{2}$ in the bicarbonate pool ocettrs (21) and thus could lead to an underestimation of the calculated exogenous oxidation rates. However, during exercise, the $\mathrm{CO}_{2}$ production $\left(\mathrm{V}_{\mathrm{CO}} \mathrm{O}_{2}\right)$ increases eight- to tenfold, leading to a physiological steadystate situation in which ${ }^{13} \mathrm{CO}_{2}$ in expired air will be in equilibrium with the ${ }^{13} \mathrm{CO}_{2} / \mathrm{T}^{13} \mathrm{CO}_{3}$ pool. It has been shown

\section{Table 2. Beverage composition}

\begin{tabular}{|c|c|c|}
\hline $\begin{array}{c}\text { Bowornge } \\
\text { Composition }\end{array}$ & $01 \%$ & $(H I)+M(r)^{\prime}$ \\
\hline $\mathrm{CTO}$, energy\% & 100 & 60 \\
\hline MCT, energy $\%$ & 0 & 40 \\
\hline $\mathrm{CHIO}, \mathrm{g} / \mathrm{l}$ & 156.2 & 93.1 \\
\hline $\mathrm{MCT}, g / !$ & 0 & 28.5 \\
\hline Energy, keJ/L (kcal/L) & $2,620(627)$ & $2,620(627)$ \\
\hline
\end{tabular}

Subjects ingested $12 \mathrm{ml} / \mathrm{kg}$ over 90 -min period. 
Table 3. Resting enrichment values and change in enrichment of breath samples at different time points us. rest sample

\begin{tabular}{rrrrrr}
\hline & \multicolumn{2}{c}{ LG } & & \multicolumn{2}{c}{ HG } \\
\cline { 5 - 6 } Time & \multicolumn{1}{c}{ CHIO } & CHO +MCT & & \multicolumn{1}{c}{ CHO } & CHO + MCT \\
\hline 0 & $-27.17 \pm 0.31$ & $-27.35 \pm 0.20$ & & $-27.06 \pm 0.17$ & $-27.10 \pm 0.19$ \\
& $0.00 \pm 0.00$ & $0.00 \pm 0.00$ & & $0.00 \pm 0.00$ & $0.00 \pm 0.00$ \\
15 & $0.13 \pm 0.09$ & $5.41 \pm 0.68$ & & $0.10 \pm 0.14$ & $3.56 \pm 0.69$ \\
30 & $-0.07 \pm 0.18$ & $8.42 \pm 0.56$ & & $0.51 \pm 0.13$ & $6.86 \pm 0.65$ \\
45 & $0.01 \pm 0.15$ & $9.84 \pm 1.04$ & & $0.55 \pm 0.12$ & $8.56 \pm 0.69$ \\
60 & $0.24 \pm 0.14$ & $11.33 \pm 0.83$ & & $0.68 \pm 0.13$ & $9.74 \pm 0.69$ \\
75 & $0.18 \pm 0.13$ & $13.04 \pm 1.16$ & & $0.73 \pm 0.13$ & $10.33 \pm 0.77$ \\
90 & $0.05 \pm 0.25$ & $13.87 \pm 0.85$ & & $0.70 \pm 0.13$ & $10.87 \pm 0.90$
\end{tabular}

Values are means $\pm \mathrm{SE}$, expressed in $\delta \%$ vs. PDB.

that the dilution of ${ }^{18} \mathrm{CO}_{2}$ becomes negligible and recovery of ${ }^{13} \mathrm{CO}_{2}$ approaches $100 \%$ after 60 min of exercise (18). Therefore, in the present study, data of exogenous MCT oxidation are presented for the $60-$ to $90-\mathrm{min}$ period unless stated otherwise.

Analysis. Blood $(10 \mathrm{ml})$ was collected into EDTA tubes and centrifuged for $4 \mathrm{~min}$. Aliquots of plasma were frozen immediately in liquid nitrogen and stored at $-40^{\circ} \mathrm{C}$ until analysis of glucose (Roche, Uni Kit III, 0710970), lactate (9), $\beta$-hydroxybutyrate (17), FFAs (Wako NEFA-C test kit, Wako Chemicals, Neuss, Germany), and glycerol (Sigma Chemical, GPOtrinder 337) on a COBAS BIO analyzer. From breath samples $\left(\dot{\mathrm{V}}_{\mathrm{CO}}, \dot{\mathrm{VO}}_{2}\right)$ and stable-isotope measurements (IRMS, Fimnigan MAT 252), total energy expenditure and oxidation rates of total fat, total CHO, and exogenous MCT were calculated. Breath samples were collected in $20 \mathrm{ml}$ Vacutainer tubes (Becton Diclkinson, Meylan Cedex, France) and stored at room temperature until analysis.

Calculations. From $\dot{\mathrm{V}}_{\mathrm{CO}_{2}}$ and $\dot{\mathrm{V}}_{2}, \mathrm{CHO}$ and fat oxidation rates were calculated by using stoichiometric equations (19)

$$
\begin{gathered}
\text { glucose oxidation }=4.585 \dot{\mathrm{V}} \mathrm{CO}_{2}-3.226 \dot{\mathrm{VO}}_{2} \\
\text { fat oxidation }=1.695 \dot{\mathrm{VO}}_{2}-1.701 \dot{\mathrm{V}} \mathrm{CO}_{12}
\end{gathered}
$$

The isotopic enrichment was expressed as the $\delta \%$ difference between the ${ }^{13} \mathrm{C} /{ }^{12} \mathrm{C}$ ratio of the sample and a kmown laboratory reference standard according to the formula

$$
\delta^{13} \mathrm{C}=\left(\frac{{ }^{13} \mathrm{C} /{ }^{12} \mathrm{C} \text { sample }}{{ }^{13} \mathrm{C} /{ }^{12} \mathrm{C} \text { standard }-1}\right) \times 10^{3}
$$

The $\delta^{13} \mathrm{C}$ was then related to an international standard, Pee Dee Belemnitella (PDB) limestone (PDB1 standard $=1.12372$ ${ }^{13} \mathrm{C} /{ }^{12} \mathrm{C}$ ratio).

The amount of exogenous MCT oxidized was calculated according to the formula

exogenous MCT oxidation

$$
=\dot{\mathrm{V}}_{2} \cdot\left(\delta_{\mathrm{bkg}}-\delta_{\mathrm{exp}}\right) /\left(\delta_{\mathrm{hkg}}-\delta_{\mathrm{ing}}\right)-1 / k
$$

where $\delta_{\text {blkg }}$ is the ${ }^{13} \mathrm{C}$ enrichment of expired air during the CHO trial (background), $\delta_{\text {exp }}$ is the ${ }^{13} \mathrm{C}$ enrichment of expired air during exercise at different time points, $\delta_{\text {ing }}$ is the ${ }^{13} \mathrm{C}$ enrichment of the MCT in the ingested CHO+MCT suspension, and $k$ is the amount of $\mathrm{CO}_{2}$ (in liters) produced by the oxidation of $1 \mathrm{~g}$ trioctanoate $\left(k=1.2369\right.$ liters $\left.\mathrm{CO}_{2} / \mathrm{g} \mathrm{MCT}\right)$.

Statistics. Analysis of variance for repeated measures was used to compare differences in substrate utilization and in

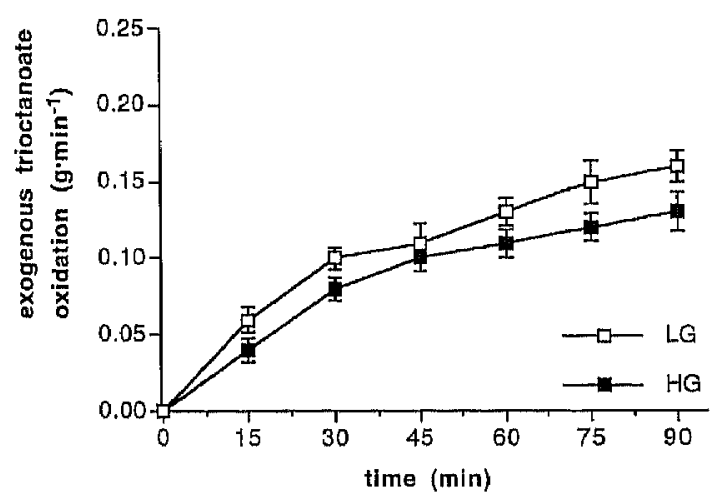

Fig. 1. Exogenous trioctanaate oxidation [medium-chain triglycerides (MCT)] from carbohydrate $(\mathrm{CHO})+\mathrm{MCT}$ suspensions during exercise in high-glycogen (HG) and low-glycogen (LG) trials. No significant differences between LG and HG were found.

blood-related parameters among the four endurance rides. A Scheffés post hoc test was used in the event of a significant $(P<0.05) F$-ratio

\section{RESULTS}

$\dot{V}_{O_{2}}$ was relatively constant throughout the experiments, and there were no differences among the four trials (Table 1). Average background ${ }^{13} \mathrm{C}$ enrichment measured from the resting breath samples was $-27.21 \pm 0.618 \%$ (Table 3). Changes in isotopic composition of expired $\mathrm{CO}_{2}$ in response to exercise are presented in Table 3. With ingestion of $\mathrm{CHO}$ (of low ${ }^{13} \mathrm{C}$ natural abundance) there was a slight, but statistically not significant, increase of ${ }^{13} \mathrm{C}$ in the expired air. In the CHO-MCT trials, the rise in ${ }^{13} \mathrm{C}$ was highly significant, reaching a $\delta \%$ difference of $\geq 10-13$ toward the end of 90-min exercise (compared with CHO experiment breath samples). There was no difference in the rates of ${ }^{13} \mathrm{CO}_{2}$ appearance in expired air between the HG and LG trials. Exogenous MCT oxidation showed a gradual increase over time both in the $L G$ and in the HG states (Fig. 1). Peak oxidation rates were reached at the end of exercise (90 $\mathrm{min}$ ) and were $0.15 \mathrm{~g} / \mathrm{min}$ (LG) and $0.13 \mathrm{~g} / \mathrm{min}$ ( $\mathrm{HG}$ ). No differences were observed between the LG and HG trials.

In Table 4, the amount of CHO and exogenous and endogenous fat oxidation during the exercise period is presented. Over the 60 - to $90-\mathrm{min}$ period, 4.24 는 $0.27 \mathrm{~g}$ of $5 \mathrm{~g}$ exogenous MCT were oxidized in the LG trial and

\begin{tabular}{|c|c|c|c|c|}
\hline & \multicolumn{2}{|c|}{ LG } & \multicolumn{2}{|c|}{$\mathrm{HG}$} \\
\hline & CHO & $\mathrm{CHO}+\mathrm{MCl}$ & CHO & $\mathrm{CHO}+\mathrm{MCI}$ \\
\hline CHO total, $g$ & $45.5 \pm 3.5^{* 1 *}$ & $38.7 \pm 3.1 *$ & $69.2 \pm 5.1$ & $60.5 \pm 5.4$ \\
\hline Fat total, g & $32.0 \pm 1.3^{*:}$ & $35,1 \pm 2.3^{\text {|k }}$ & $19.9 \pm 1.3$ & $25.7 \pm 2.4$ \\
\hline Fat exo (MCT), $g$ & $0.0 \pm 0.0$ & $4.2+0.8$ & $0.0 \pm 0.0$ & $3.6 \pm 0.3$ \\
\hline Fat endo, $\mathrm{g}$ & $32,0 \pm 1.3^{*}$ & $30.9 \pm 2.0^{;:}$ & $19.9 \pm 1.3$ & $22.2 \pm 2.0$ \\
\hline
\end{tabular}

Table 4. Total CHO oxidation, endogenous fat, and exogenous $M C T$ oxidation during 60- to 90-min period in LG and HG trials

Exo, exogenous; endo, endogenous. "Significant difference between LG and $\mathrm{HG}(P<0.05)$. 
$3.45 \pm 0.26 \mathrm{~g}$ in the $\mathrm{HG}$ trial. This represented 85 and $69 \%$ of the total amount of MCT ingested, respectively. Exogenous MCT contributed 7.6\% to total energy expenditure in the LG trial and $6.5 \%$ in the $\mathrm{HG}$ trial (during the 60 - to $90-\mathrm{min}$ period). These differences, however, were not statistically significant.

No differences in energy expenditure between the four trials were observed (Fig. 2). There were large differences in substrate utilization between the $\mathrm{HG}$ and LG trials, but differences between the CHO and CHO +MCT trials were not statistically significant. Total CHO utilization over $90 \mathrm{~min}$ was significantly higher in the HG trials [63 (CHO) and $53 \%(\mathrm{CHO}+\mathrm{MCT})$ of total energy expenditure compared with the LG trials; 37 (CHO) and $33 \%(\mathrm{CHO}+\mathrm{MCT})$ of total energy expenditure, respectively].

Resting plasma FFA concentrations were significantly higher in the LG trials (Fig. 3). Plasma FFA concentrations rose during exercise in all trials, except for the glycogen-loaded trial with CHO supplementation. FFA concentrations were elevated in the CHO + MCT trials compared with the CHO trials and in the LG trials compared with the HIG trials. Glycerol concentrations were not significantly different in the resting situation and increased during exercise in all trials (Fig. 3). However, the increase was significantly greater in the LG trials from $15 \mathrm{~min}$ on. No difference was observed between CHO and CHO+MCT. Plasma
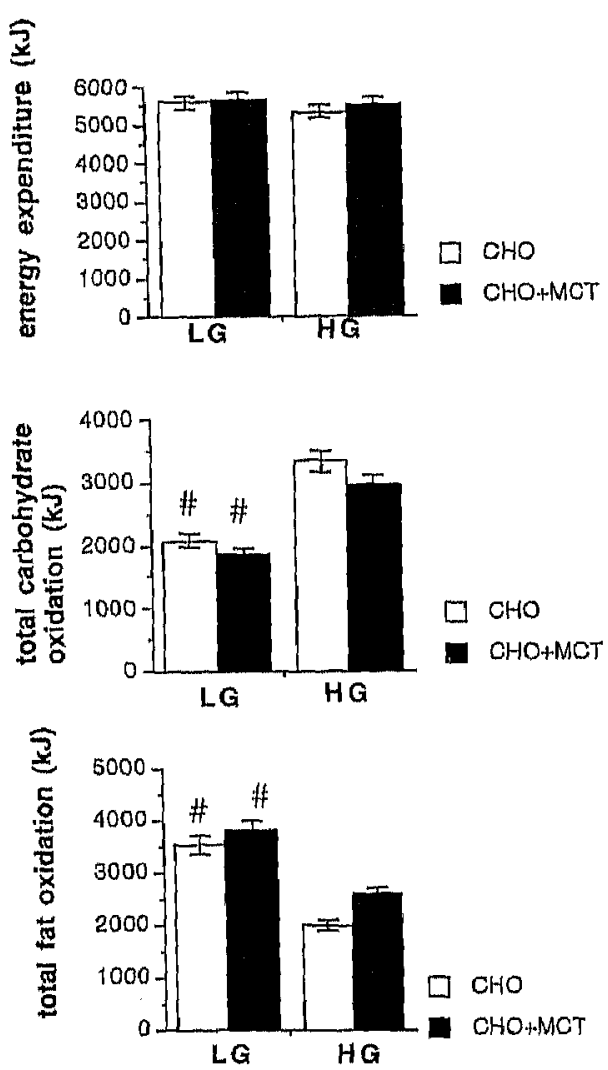

Fig. 2. Total energy expenditure, CHO oxidation, and fat oxidation over 90 min of exercise with ingestion of CHOs or a CHO+MCL suspension in $H G$ and $L G$ trials. \#Signifieant difference $(P<0.001)$ between $L G$ and $H G$. $\beta$-hydroxybutyrate was significantly elevated after 30 min until the end of exercise for the MCT-containing drinks (Fig. 3). There was no significant difference between $H G$ and $L G$. There were no large changes in plasma glucose concentrations (Fig. 3). At 15 and 30 min, however, a slight but significant higher glucose concentration was observed in the HG-CHO trial compared with the LG trials.

\section{DISCUSSION}

Exogenous MCT oxidation. The amount of MCT oxidized was $\sim 69-85 \%$ of the amount ingested during the final $30 \mathrm{~min}$ of exercise, representing $6.5-7.6 \%$ of total energy expenditure. When calculated over the entire $90 \mathrm{~min}$ of exercise, and neglecting a possible delay in the ${ }^{19} \mathrm{CO}_{2}$ appearance in the expired air due to entrapment in the bicarbonate pool, about one-third of the ingested amount was oxidized, covering 5.2-5.9\% of energy expenditure, which is in accordance with previous findings of others $(7,16)$ and ourselves (12). Massicotte et al. (16) showed that $54 \%$ of $25 \mathrm{~g}$ MCT was oxidized during $120 \mathrm{~min}$ of exercise at $65 \% \mathrm{~V}_{\mathrm{m}}$ mx . The MCT, provided in a preexercise meal, contributed $7 \%$ to total energy expenditure. Décombaz et al. (7) reported that $30 \%$ of a preexercise MCT meal ( $25 \mathrm{~g}$ ) was oxidized during $120 \mathrm{~min}$ of exercise at a comparable exercise intensity $\left(60 \% \dot{V} \mathrm{O}_{2 \mathrm{mnx}}\right)$. MCT contributed $11 \%$ to the energy yield.

We recently reported that the rate of MCT oxidation was maximally $70 \%$ of the rate of ingestion of MCT provided as MCT or in a CHO +MCT suspension during 180 min of exercise (12). MCT contributed 3-7\% to total energy expenditure. In this study, peak MCT oxidation rates as well as the percentage of ingested MCT that was oxidized (i.e., $69-85 \%$ ) were somewhat higher. The high oxidation rates of MCT suggest that the MCFA are very rapidly oxidized once they are in the systemic circulation.

The time course of 'tis $\mathrm{CO}_{2}$ appearance in the expired air is similar to that of glucose: a plateau in enrichment is reached after $\sim 60 \mathrm{~min}$. The time required to reach maximal oxidation rates is dependent on several factors, including dilution in the bicarbonate pool, gastric emptying, and absorption.

Recently, we examined the gastric emptying rate of CHO-MCT emulsions (3). Four equicaloric CHO+MCT suspensions were studied with varying MCT contents. These suspensions varied from no MCT to maximally $30 \%$ MCT. It appeared that the suspension that emptied most rapidly from the stomach was the suspension with the highest concentration of MCT, whereas the CHO solution with no MCT was the slowest. Therefore, it was concluded that MCT did not reduce gastric emptying of CHO + MCT suspensions and that CHO content may be a major factor determining the gastrie emptying rate.

In vitro studies $(8)$ as well as in vivo studies $(8,15)$ have shown that the rate of absorption is fast compared 

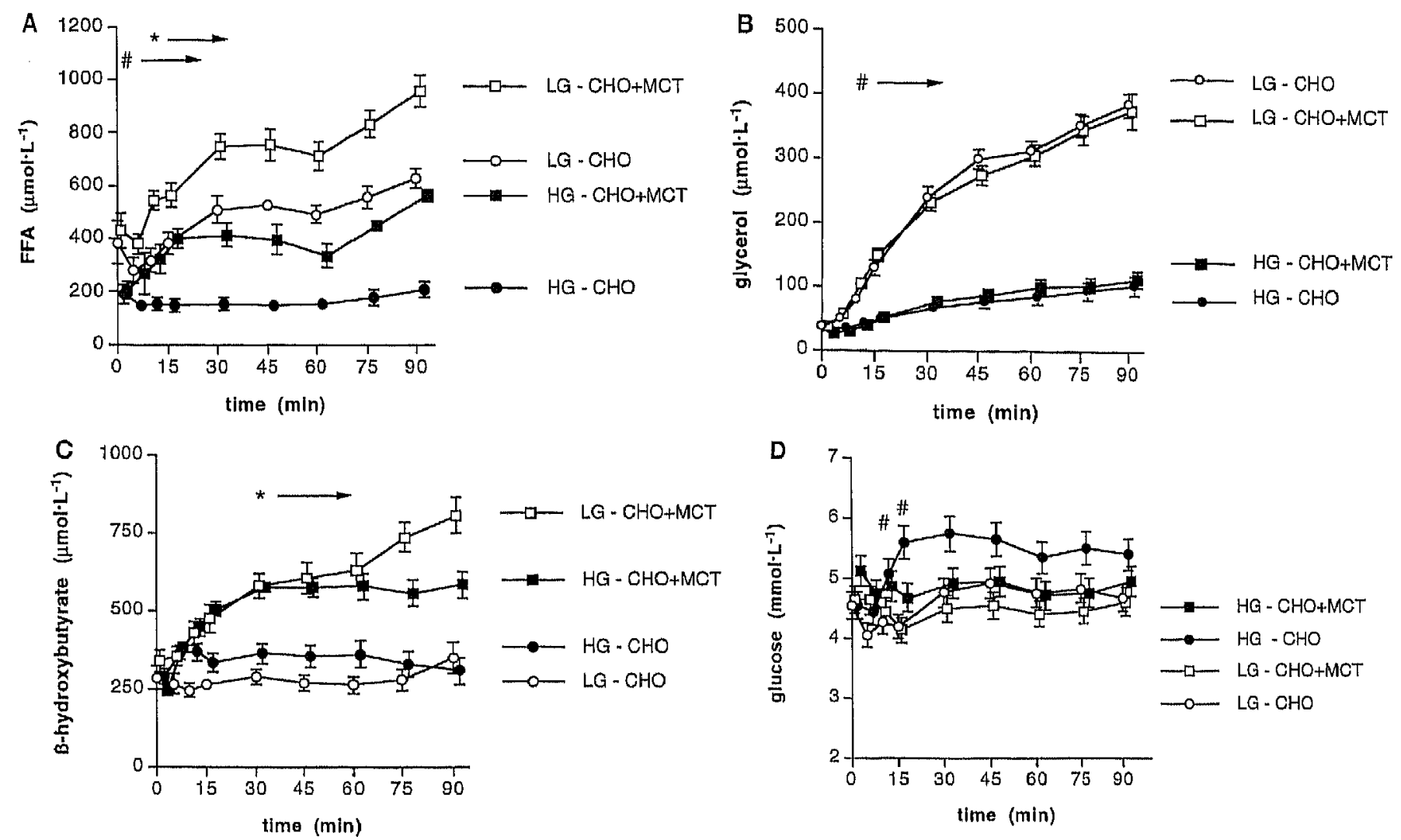

Fig. 3. Plasma free fatty acids (FFA; $A$ ), glycerol $(B)$, $\beta$-hydroxybutyrate $(C)$, and glucose $(D)$ concentrations during 90 min of exercise in LG and HG trials with CHO or CHO+MCT ingestion. "significant difference $(P<0.05)$ between $\mathrm{CHO}$ and MCT until end of exercise; \# significant difference $(P<0.05)$ between LG and HG until end of exercise.

with long-chain triglycerides and can occur even in the absence of lipase $(6,8)$. Therefore, it seems that both the rate of gastric emptying and the rate of absorption of MCT are comparable to those of glucose, which is reflected in a similar time course of ${ }^{13} \mathrm{CO}_{2}$ appearance in expired gases.

Although total fat utilization was significantly higher, MCT oxidation was not elevated in the LG trials. After a glycogen-depletion protocol as applied in the present study, muscle glycogen (13) and muscle triglycerides (5) are drastically reduced. Several studies have shown that late in exercise the rate of disappearance of glucose and FFA is increased $(22,23)$, providing evidence for the increased reliance on plasma glucose and FFA. Therefore, we hypothesized that plasma FFA, and thus also plasma MCFA oxidation, would even be higher in the LG trials. The glycogen-depletion trial, however, had no effect on exogenous MCT oxidation in the present study. This makes it more likely that the main limiting factor for oxidation of MCT is the entrance of MCFA in the systemic circulation, as suggested previously (12).

Ingestion of MCT did not significantly influence total CHO utilization. This is in agreement with previous studies $(7,16,25)$ that also found no changes in endogenous $\mathrm{CHO}$ oxidation or muscle glycogen utilization with MCT ingestion.
Substrate / metabolite concentrations. Glycerol concentrations did not change as a result of MCT ingestion. Probably MCT are hydrolyzed in the lumen, and both MCFA and glycerol enter the liver directly via the portal vein. The data suggest that glycerol is converted into glucose by gluconeogenesis in the first pass through the liver. In the glycogen-depleted state, however, lipolysis in adipose tissue is stimulated during exercise, and large amounts of glycerol enter the main circulation. The increase in plasma $\beta$-hydroxybutyrate concentration seems to suggest that part of the MCFA are oxidized in the liver. Ketone bodies are formed in the liver when the production of acetyl-CoA exceeds the energy needs of the hepatic tissue. It is known that MCTs are highly ketogenic (2). In this study, MCT supplementation elevated $\beta$-hydroxybutyrate concentrations markedly, which is in accordance with previous studies giving MCT as a preexercise feeding (1, 7, 11, 16, 25).

Summary. We conclude that lowering of muscle glycogen on the previous day substantially increases total fat oxidation during 90 min of exercise in comparison with CHO loading the previous day. However, no effect was seen on the oxidation of MCTs that were coingested with $\mathrm{CHO}$ s during $90 \mathrm{~min}$ of exercise. 
Address for reprint requests: A. E. Jeulkendrup, Dept. of Human Biology, Univ, of Limburg, PO Box 616, 6200 MD Maastricht, The Netherlands.

Received 5 July 1995; accepted in final form 24 October 1995.

\section{REFERENCES}

1. Auclair, E., P. Satabin, E. Servan, and C. Y. Guezennec Metabolic effects of glucose, medium chain triglyceride and long-chain triglyceride feeding before prolonged exercise in rats. Eur. J. Appl. Physiol. Occup. Physiol. 57: 126-131, 1988.

2. Bach, A. C., and V. K. Babayan. Medium-chain triglycerides: an update. Am. J. Clin. Nutr. 36: 950-962, 1982.

3. Beckers, E. J., A. E. Jeukendrup, F. Brouns, A. J. M. Wagenmakers, and W. H. M. Saris. Gastric emptying of carbohydrate-medium chain triglyceride suspensions at rest. Int. J. Sports Med. 13: 581-584, 1992.

4. Bremer, J. Carnitine--metabolism and functions. Physiol. Rev. 63: $1420-1479,1983$.

5. Brouns, F., W. H. M. Saris, E. Beckers, H. Adlercreutz, G. J. Van Der Vusse, H. A. Keizer, H. Kuipers, P. Menheere, A. J M. Wagenmakers, and F. Ten Hoor. Metabolic changes induced by sustained exhaustive cycling and diet manipulation. Int. J. Sports Med. 10: S49-\$62, 1989

6. Chow, B. P. C., E. A. Sgaffer, and H. G. Parsons. Absorption of triglycerides in the absence of lipase. Can.J. Physiol. Pharmacol. 68: 519-523, 1990 .

7. Decombaz, J., M.-J. Arnaud, H. Milon, H. Moesch, G. Philippossian, A.-L. Thelin, and H. Howald. Energy metabolism of medium chain triglycerides versus carbohydrate during exercise. Eur. J. Appl. Physiol. Occup. Physiol. 52: 9-14, 1983.

8. Greenberger, N. J., J. B. Rodgers, and K. J. Isselbacher. Absorption of medium and long-chain triglycerides: factors influencing their hydrolysis and transport. J. Clin. Invest. 45: 217$227,1966$.

9. Gutmann, I., and A. W. Wahlefeld. $L-(+)$-Lactate, Determination With Lactate Dehydrogenase and NAD (2nd English ed.) New York: Academic, 1974, p. 1464-1468.

10. Havel, R. J., A. Naimark, and F. Borchgrevink. Tumover rate and oxidation of free fatty acids of blood plasma in man during prolonged exercise: studies during continuous infusion of palmitate-1 $1{ }^{14}$ C. J. Clin. Invest. 42; 1054-1063, 1963.

11. Ivy, J. L., D. L. Costill, W. J. Fink, and E. Magliseho. Contribution of medium and long-chain triglyceride intake to energy metabolism during prolonged exercise. Int. J. Sports Med. 1: $15-20,1980$.

12. Jeukendrup, A. E., W. H. M. Saris, P. Schrauwen, F. Brouns and A. J. M. Wagenmakers. Metabolic availability of ora medium-chain triglycerides coingested with carbohydrates duxing prolonged exercise. J. Appl. Physiol. 79: 756-762, 1995

13. Kuipers, H., W. H. M. Saris, F. Brouns, H. A. Keizer, and C. Ten Bosch. Glycogen synthesis during exercise and rest with carbohydrate feeding in males and females. Int. J. Sports Med. 10: $\$ 63-\mathrm{S} 67,1989$.

14. Kuipers, H., F. T. J. Verstappen, H. A. Keizer, P. Geurten, and G. Van Kranenburg. Variability of aerobic performance in the laboratory and its physiologic correlates. Int. J. Sports Med. 6: 197-201, 1985 .
15. Linscheer, W. G., J. F. Patterson, E. W. Moore, R. J. Cler. mont, S. J. Robins, and T. C. Chalmers. Medium and longchain fat absorption in patients with cirrhosis. J. Clin. Invest. 45: $1317-1325,1966$.

16. Massicotte, D., F. Péronnet, G. R. Brisson, and C. HillaireMarcel. Oxidation of exogenous medium-chain free fatty acids during prolonged exercise-comparison with glucose. J. Appl. Physiol. 73: 1334-1339, 1992.

17. Moore, J. J., M. Marcus, and S. M. Sax. Kinetic assay of $\beta$-hydroxybutyrate in plasma with COBAS BIO centrifugal ana. lyzer. Clin. Chem. 73: 1334-1339, 1982.

18. Pallikarakis, N., N. Sphiris, and P. Lefebvre. Influence of the bicarbonate pool and on the occurence of ${ }^{19} \mathrm{CO}_{2}$ in exhaled air. Eum J. Appl. Physiol. Occup. Physiol. 63: 179-183, 1991.

19. Péronnet, F., and D. Massicotte. Table of nonprotein respiratory quotient: an update. Can. J. Sport Sci. 16:23-29, 1991.

20. Rehrer, N. J., A. J. M. Wagenmakers, E. J. Beckers, D. Halliday, J. B. Leiper, F. Brouns, R. J. Maugham, K. Westerterp, and W. H. M. Saris. Gastric emptying, absorption and carbohydrate oxidation during prolonged exercise. $J$. Appl. Physiol. 72: 468-475, 1992.

21. Robert, J. J. J. Koziet, D. Chauvet, D. Darmaun, J. F. Desjeux, and V. R. Young. Use of ${ }^{1:} \mathrm{C}$-labeled glucose for estimating gltucose oxidation: some design considerations. J. Appl. Physiol. 63: 1726-1732, 1987.

22. Romijn, J. A., E. F. Coyle, L. S. Sidossis, A. Gastaldelli, J. F. Horowitz, E. Endert, and R. R. Wolfe. Regulation of endogenous fat and carbohydrate motabolism in relation to exercise intensity. Am. J. Plysiol, 265 (Endocrinol. Metab. 28): T380E391, 1993.

23. Romijn, J. A., and R. R. Wolfe. Reffects of prolonged exercise on endogenous substrato supply and atilization. In: Lnergy Melabo. lism in Exercise and Spont. Dubuque, IA: Brown \& Benelmark, 1992 , p. 207-234.

24. Saris, W. H. M., B. H. Goodpaster, A. E. Jeukendrup, F. Brouns, D. Halliday, and A. J. M. Wagenmakens. Wxogenous carbohydrate oxidation from different carbohydrato sources during oxercise. J. Appl. Pingsiol. 75: 2168-2172, 1993.

25. Satabin, P., P. Portero, G. Deller, J. Bricout, and C.M Guezennec. Motalolic and hommonal rosponses lo lipid and carbohydrate diets duting exoroiso in man. Med. Stei. Sports Exercise 19: 218-223, 1987.

26. Turcotite, L. P., E. A. Richter, and B. Kions. Incrensed plasma FFA uptake and oxidation during prolonged exorcise ín trained vs, untrained humang. Am. al, Physiol, 262 (Sndowinol. Metal. 25): $2791-1799,1992$.

27. Wagenmakers, A. J. M., I. Brouns, W. H. M. Saxis, and D. Halliday. Oxidation matos of orally ingested embolsydrates during prolonged oxoreise in mon. I. Appl. Plywsiol. 75: 277 . $2780,1993$.

28. Wagenmakers, A. J. M., N. J. Rehrer, F. Brouns, W. I., M Saris, and D. Halliday. $\mathrm{Brenth}^{1 / 1} \mathrm{CO}_{2}$ backgeound on richmant at rest and during exercise: dict-polated difforencos between Europe and Amoricu. J. Appl. Thysiol. 74 : 2353-2357, 1993.

29. Wahren, J., P. Felig, G. Ahlborg, and L. Jorfoldt. Glucose metabolism during leg axorcise in man. of, Clin. Invest. 50: $2715-2725,1971$. 